\title{
Educação profissional continuada: uma análise investigativa de seus benefícios na visão dos auditores independentes registrados no CNAI e vinculados ao CRC-MT
}

\section{Aloisio Rodrigues da Silva, Wellen Kayzi Moraes de Almeida e Silva, Sofia Ines Niveiros}

\author{
Departamento de Ciências Contábeis \\ Universidade Federal de Mato Grosso \\ Bacharel em Ciências Contábeis \\ Universidade Federal de Mato Grosso \\ Departamento de Ciências Contábeis \\ Universidade Federal de Mato Grosso
}

O objetivo desta pesquisa é identificar os benefícios decorrentes da exigência do cumprimento da educaçáo continuada para auditores independentes na visão dos profissionais registrados no CNAI associados ao CRCMT. Muito se conhece sobre as transiçôes periódicas que existem nas normas e legislaçấo brasileira que afetam diretamente o exercício das atividades contábeis, em especial, da auditoria das demonstraçóes financeiras que são elaboradas pela governança corporativa das organizaçóes de negócios, às vezes, considerados desastrosos e alarmantes tanto do ponto de vista dos contadores, quanto dos contribuintes. As informaçôes colhidas foram essenciais na identificação dos benefícios que as exigências do cumprimento do programa de educação profissional continuada proporcionam para a consolidação do exercício das atividades do auditor independente na opiniấo dos entrevistados. Em relaçáo à metodologia, esta pesquisa classifica-se como levantamento ou survey, cuja tipologia se caracteriza como descritiva e de natureza qualitativa. Por fim, por meio da análise comparativa dos dados, observou-se que $100 \%$ dos auditores entrevistados estão preocupados em estarem atualizados, e estão em busca do aprimoramento profissional. Nesse contexto, cabe as capacitadoras investirem mais em trabalhos e cursos de aprimoramento.

Palavras-chave: tipos de auditoria, governança corporativa, atividades do auditor, normas de auditoria.

\section{Educación profesional continuada: un análisis investigativo de sus beneficios en la visión de los auditores independientes registrados en el CNAI y vinculados al CRC-MT}

El objetivo de esta investigación es identificar los beneficios derivados de la exigencia del cumplimiento de la educación continuada para auditores independientes en la visión de los profesionales registrados en el CNAI asociados al CRCMT. Se conoce mucho sobre las transiciones periódicas que existen en las normas y legislación brasileña que afectan directamente el ejercicio de las actividades contables, en especial, de la auditoría de los estados financieros que son elaboradas por el gobierno corporativo de las organizaciones de negocios, a veces considerados desastrosos y alarmantes tanto desde el punto de vista de los contadores, como de los contribuyentes. Las informaciones recogidas fueron esenciales en la identificación de los beneficios que las exigencias del cumplimiento del programa de educación profesional continuada proporcionan para la consolidación del ejercicio de las actividades del auditor independiente en 
la opinión de los entrevistados. En relación a la metodología, esta investigación se clasifica como levantamiento o survey, cuya tipología se caracteriza como descriptiva y de naturaleza cualitativa. Por último, a través del análisis comparativo de los datos, se observó que el 100\% de los auditores entrevistados están preocupados por estar actualizados, y están en busca del perfeccionamiento profesional. En este contexto, cabe las capacitadoras invertir más en trabajos y cursos de perfeccionamiento.

Palabras clave: tipos de auditoría, gobierno corporativo, actividades del auditor, normas de auditoría.

\section{Continued professional education: An investigative analysis of its benefits in the view of the independent auditors registered at the CNAI and linked to the CRC-MT}

The objective of this research is to identify the benefits arising from the requirement of compliance with continuing education for independent auditors in the view of professionals registered in the CNAI associated with CRCMT. Much is known about the periodic transitions that exist in Brazilian norms and legislation that directly affect the exercise of accounting activities, especially the audit of financial statements that are elaborated by the corporate governance of business organizations, sometimes considered disastrous and alarming both from the point of view of accountants, and from taxpayers. The information collected was essential in identifying the benefits that the requirements of compliance with the continuing professional education program provide for the consolidation of the activities of the independent auditor in the opinion of the interviewees. Regarding the methodology, this research is classified as a survey or survey, whose typology is characterized as descriptive and of a qualitative nature. Finally, through the comparative analysis of the data, it was observed that $100 \%$ of the interviewed auditors are worried about being updated, and are looking for professional improvement. In this context, it is up to the trainers to invest more in jobs and improvement courses.

Keywords: Audit types, Corporate governance, Auditor's activities, Auditing standards.

\section{Introduçáo}

A contabilidade moderna ocupa papel significativo nas organizaçôes, pois estas, por meio dos responsáveis pela governança corporativa tomam decisóes, quase todas relevantes e vitais para o sucesso do negócio. Essa situação não é diferente para os usuários externos que necessitam de dados que geram informaçóes corretas e úteis para subsidiar os processos de tomadas de decisôes (Marion, 2015).

A auditoria tem um papel fundamental para que a contabilidade atinja seus fins, uma vez que constata se as informaçóes são fidedignas à realidade da empresa, ou seja, determina a integridade do sistema de controle interno contábil, das demonstraçóes financeiras, como o resultado das operaçóes, assessorando a empresa no aprimoramento dos controles internos contábeis (Attie, 2011; Crepaldi, 2009; Franco \& Marra, 2009).

Uma das áreas da contabilidade que aumenta o grau de confiabilidade das informaçóes apresentadas nos relatórios contábeis é a auditoria (Wanderley, 2011). Quanto aos tipos se classificam em três categorias: auditoria contábil, operacional e da conformidade. Por outro lado, quanto à forma do relacionamento do auditor com a entidade se classifica como sendo interna ou externa (Briti, 2010; Sá, 2009).

Guardando sincronia com a NBC TI 01, aprovada pela Resoluçáo CFC no 986/03, alterada pela Resolução CFC no 1.329/11 a operacional vem sendo concebida como sendo os exames, análises, avaliaçôes, levantamentos e comprovaçóes, metodologicamente 
estruturados para a avaliação da integridade, adequação, eficácia, eficiência e economicidade dos processos, dos sistemas de informaçóes e de controles internos integrados ao ambiente, e de gerenciamento de riscos, com vistas a assistir à administraçáo da entidade no cumprimento de seus objetivos. Nota-se que este trabalho é normalmente executado pelos auditores internos, ou seja, empregados da organização auditada.

Já a auditoria contábil vem sendo denominada com auditoria das demonstraçóes financeiras e de acordo com Franco e Marra (2009) e Wanderley (2011) compreende a técnica contábil que com base em procedimentos específicos que lhe são peculiares, aplicados na verificação de registros e documentação comprobatória das operaçôes realizadas, inspeçôes e na coleta informaçôes e confirmaçóes consoantes com o controle do patrimônio possibilitam julgar se sua escrituraçáo contábil foi executada em conformidade com as normas de contabilidade e se os relatórios contábeis elaborados pela empresa refletem adequadamente sua situação patrimonial e o real desempenho do período considerado.

No Brasil o profissional da contabilidade para exercer a função de auditoria independente deve se submeter ao exame de qualificaçáo técnica, para compor o Cadastro Nacional de Auditores Independentes (CNAI), criado em 2005, por meio da Res. CFC no 1.019, que foi revogada pela Res. CFC no $1495 / 15$, dispondo sobre o referido cadastro e contempla as diretrizes da NBC TA 13, que já se encontra em sua segunda revisão (R2) - Exame de Qualificação Técnica. Conforme estabelecido, no item 7, da NBC PG 12 (R2) (2016), para manter-se nesse cadastro o auditor independente precisa cumprir educação profissional continuada correspondente a, no mínimo, 40 (quarenta) pontos por ano-calendário.
O campo de atuação da contabilidade e, consequentemente, da auditoria é bastante diversificado e sofre mudanças significativas com muita frequência o que exige o aprimoramento contínuo daqueles que atuação nessa profissão e função.

No Brasil, a educação profissional continuada foi instituída por meio da Res. CFC no 945/02, que aprovou a NBC P 4, tendo sido o seu marco inicial, alterada pela Res. CFC no 995/04, revogada pela Res. CFC no 1060/05, revogada pela Res. CFC no 1074/06, revogada pela Res. 1.146/08, que transformou a NBC P 4, em NBC PA 12. Esta última também foi revogada por meio da Res. CFC no 1.377/11 a qual deu nova redação à NBC PA 12 que em 17/12/13 foi transformada na NBC PG 12, que já passou por três revisôes, até dezembro de 2017.

A NBC PG 12 (R3), (2017), regulamenta a educação continuada de auditores independentes e peritos contábeis objetivando sua capacitação da atualização e expansão de conhecimentos. Nesse sentido foi que a Comissão de Valores Mobiliários - CVM, através de sua nota explicativa a CVM (Instrução 308, 1999) esclarece que os auditores independentes registrados na CVM deverão manter um programa de educação continuada consoante às diretrizes aprovadas pelo CFC e pelo IBRACON.

Diante do exposto, as problemáticas discutidas neste tópico exigem a busca de respostas ao seguinte questionamento: Quais são os benefícios da exigência da educação continuada, segundo as opiniōes dos auditores independentes registrados no CNAI associados ao CRCMT? Portanto o objetivo geral desta pesquisa é identificar os benefícios decorrentes da exigência do cumprimento da educaçáo continuada para auditores independentes na visão dos profissionais registrados no CNAI associados ao CRCMT. 
O estudo justifica-se pela necessidade de manutenção da competência e zelo profissional às exigências do mundo globalizado. As empresas têm interesse na credibilidade e confiabilidade junto aos clientes e stakeholders, para isso contratam os serviços especializados de auditoria periodicamente. Visando um serviço de qualidade o CFC criou o Cadastro Nacional de Auditores Independentes que estabeleceu que o contador que desejar atuar como auditor independente deve se submeter ao Exame de Qualificação Técnica e cumprir quarenta pontos anuais de educação profissional continuada. Esta pesquisa é relevante também uma vez que busca verificar os benefícios decorrentes da exigência do cumprimento da educação continuada para auditores independentes.

\section{Referencial teórico}

\subsection{Normas Brasileiras de Contabilidade - NBC}

As NBC são compostas por um conjunto de procedimentos e regulamentos de conduta que devem ser vistos como requisito para a atuação da profissão contábil, elas devem estar de acordo com as normas internacionais existentes. As Normas podem ser classificadas em Norma Técnica e Profissional, sendo que ambas estabelecem preceitos de conduta profissional e padróes técnicos para o adequado exercício profissional.

A estrutura das NBC foi definida através da Resolução $\mathrm{n}^{\circ} 1.295$ (2010) que foi revogada pelo CFC Resolução 1.328 (2011); nesta encontra-se o Art. $3^{\circ}$, onde as Normas Profissionais são estruturadas em I - Geral - NBC PG; II - do Auditor Independente - NBC; III - do Auditor Interno - NBC PI; e IV - do Perito - NBC PP.

As normas profissionais estabelecem regras de exercício profissional, caracterizando-se pelo prefixo «NBC P». Enquanto as normas técnicas estabelecem conceitos doutrinários, regras e procedimentos aplicados de
Contabilidade, caracterizando-se pelo prefixo «NBC T», e conforme o Art. $4^{\circ}$ desta Norma é estruturada em nove itens. Relacionados com a Auditoria encontramos o III - de Auditoria Independente de Informação Contábil Histórica - NBC TA - são as NBC aplicadas à Auditoria convergentes com as Normas Internacionais de Auditoria Independente emitidas pela IFAC; o VII - de Auditoria Interna - NBC TI - são as NBC aplicáveis aos trabalhos de Auditoria Interna; e o IX - de Auditoria Governamental - NBC TAG - são as NBC aplicadas à Auditoria Governamental convergentes com as Normas Internacionais de Auditoria Governamental emitidas pela Organização Internacional de Entidades Fiscalizadoras Superiores (INTOSAI).

Essa organizaçáo de regulamento foi obtida a fim de que estabeleça conformidade com as normas internacionais, visando a padronização de elaboração dos trabalhos, tendo como base os princípios contábeis. Sendo assim, estas estruturas servem para identificar minuciosamente o seu alcance em cada setor contábil, já que o objetivo das normas é orientar os profissionais para que exerçam suas atividades sem dificuldades (Longo, 2011).

Ou seja, a nova estrutura das NBC tem somente o intuito de auxiliar o usuário, a fim de que possa indicar a direção a ser seguida. É importante ressaltar que cada norma deverá ser aplicada quando houver necessidade, isso irá depender de qual circunstância o contador se encontrar.

\subsection{Normas Brasileiras de Contabilidade Profissionais do Auditor Independente}

As NBC classificam-se em profissionais e técnicas. Conforme (Attie, 2011), assim como em diversas áreas, na auditoria também foram estabelecidos alguns padrōes técnicos a serem seguidos, a fim de que possam maximizar a qualificação dos trabalhos de auditoria, 
é também onde o auditor se baseia para que seu parecer possa ser mais fidedigno.

\subsubsection{Controle de qualidade para auditores independentes}

Existem normas que regulamentam as firmas de auditoria, especificando os objetivos e obrigaçóes da mesma, podendo ser pessoa física ou jurídica. Almeida (2012), diz que esta norma trata das responsabilidades singulares do auditor que usualmente está em conformidade com os Procedimentos de controle de qualidade e também deixa claro que esta norma precisa ser lida simultaneamente com as exigências éticas cruciais.

A norma é a NBC PA 01 que está diretamente ligada a Norma Técnica NBC TA 220, que trata do controle de qualidade da auditoria das demonstrações contábeis.

Diante do exposto, é válido afirmar, que as firmas de auditoria precisam seguir um rigoroso padrão de qualidade, onde envolve responsabilidade da liderança, exigências éticas relevantes, aceitação e continuidade do relacionamento com clientes, recursos humanos, documentação do trabalho, monitoramento, entre outros. Tudo isso direciona o auditor a realizar um trabalho bem-intencionado e impecável.

\subsubsection{Independência nos trabalbos de auditoria, revisáo e asseguraçáo}

Os requisitos de independência para trabalhos de auditoria e de revisão são tratados na NBC PA 290. Caso o cliente for de asseguração, esta norma também pode ser aplicada. Pode existir circunstâncias em que o relatório de asseguração incluir restrição de uso e distribuição, existe a possibilidade desta norma ser modificada conforme introduzem os itens 21 a 27 da mesma.

O CFC (NBC PA 290 (R2), 2017) traz independência nos trabalhos, ou seja, o auditor executa seu trabalho isento dos interesses das entidades auditadas para que assim, seus serviços tenham objetividade. Ainda, esta norma descreve que: «Os trabalhos de asseguração destinam-se a aumentar o grau de confiança dos usuários previstos no resultado da avaliaçáo ou mensuração de objeto com base em critérios». Em síntese, os trabalhos de asseguração visam passar mais credibilidade aos usuários interessados em determinada atividade da entidade.

\subsubsection{Revisáo externa de qualidade pelos pares}

Prevista pela Resolução do CFC No. 1.323/11, a NBC PA 11 (2011), traz informes a respeito da revisão externa de qualidade dos pares que pode ser conceituado como «[...] o exame realizado por auditor independente nos trabalhos de auditoria executados por outro auditor independente».

O CFC na Resolução 1.323/11 (2011) descreve que o objetivo desta Norma é a avaliação dos procedimentos adotados com vistas a assegurar a qualidade dos trabalhos desenvolvidos. A norma aplica-se exclusivamente aos auditores independentes com registro na CVM (Comissão de Valores Mobiliários), é realizada a cada quatro anos, visando alcançar o desempenho profissional da mais alta qualidade. Pinho (2007) potencializou que a confidencialidade e a independência são fatores essenciais desta norma e ainda estabeleceu quesitos quanto aos prazos e conteúdo dos relatórios.

\subsubsection{Exame de qualificação técnica e o CNAI}

O CNAI está regulamentado com base na Resolução do CFC No 1.109/07, tendo como premissa a NBC PA 13. Esta Norma aplica-se aos Contadores que visam obter sua inscrição no CNAI, desde que se certifiquem que estão com situação regular junto ao CRC.

Este exame é realizado pelo CFC e é composto por uma prova escrita, contendo quarenta questóes objetivas e quatro dissertativas, o exame é aplicado pelo menos 
uma vez ao ano, e o contador para ser aprovado precisa acertar no mínimo cinquenta por cento da prova objetiva e dissertativa.

De acordo com o CFC (NBC PA 13, 2015) o objetivo principal é de «[...] aferir o nível de conhecimento e a competência técnico-profissional necessários para atuaçáo na área da Auditoria Independente». De acordo com a Resolução CFC No 1.109/07 o registro possui validade de um ano, sendo revalidado com comprovação do programa de educação continuada.

\subsubsection{Normas profissionais de auditor independente e sua regulamentaçáo no Brasil}

Pinho (2007) reforça que a presença do poder público, na fase do auge da auditoria, foi decisiva através de diversas leis que tiveram que impor o aparecimento fixo da auditoria e do auditor independente. $\mathrm{O}$ início, segundo Franco e Marra (2009) foi a lei de $N^{\circ} 4.728$ (1965), primeira lei dos mercados de capitais, onde torna a auditoria legal e obrigatória.

As leis que possuem maior representatividade nesse ramo é a Lei $n^{\circ} 6.404 / 76$ e a Lei $n^{\circ} 6.385 / 76$, pois através destas leis a auditoria se expandiu de forma significativa, tomando seu devido lugar no mercado.

Niyama, Costa, Dantas e Borges (2011) ressalta a importância da regulamentação em consequência dos escândalos corporativos do início dos anos 2000, quando foram constatados vários casos de auditoria divulgar informaçóes com falhas, o que resultou em mudanças nas regras de governança da profissão. Em suma, a auditoria continua ganhando força até hoje, em virtude de que os empresários, sócios e acionistas, buscam um controle interno com o mínimo de erro e zero fraude em suas entidades.
Portanto, foi através da ocorrência de diversos escândalos acontecendo com muita frequência que os empresários começaram se preocupar ainda mais com a imagem que sua entidade passa aos usuários das informaçôes contábeis, pois através das Normas de auditorias, é possível entấo emitir pareceres mais precisos e fidedignos, a fim de passar uma maior credibilidade referente às demonstraçôes financeiras e afins aos seus clientes.

\subsection{A Educaçáo Profissional Continuada no Brasil}

O início do programa da educação continuada para auditores ocorreu no ano de 2003, através da Resolução CFC n ${ }^{\circ} 945$, cujo histórico é delineado na introdução deste artigo, e portanto esta atualmente em vigência no Brasil, sendo reconhecida como Educação Profissional Continuada estando regulamentada por meio da NBC PG 12 (R3).

\subsubsection{Programa de Educaçáo Continuada do CFC}

Um efetivo programa de educação continuada tem como principal objetivo trazer crescimento qualitativo a toda equipe técnica da auditoria, dando-lhe contribuiçôes que desenvolvam suas capacidades pessoais, técnicas e gerenciais.

De acordo com a NBC PG 12 (R3), a Educação Profissional Continuada é assim definida:

[...] atividade formal e reconhecida pelo CFC, que visa manter, atualizar e expandir os conhecimentos técnicos e profissionais, indispensáveis à qualidade e ao pleno atendimento às normas que regem o exercício da atividade de auditoria de demonstraçôes contábeis.

Por ser essencial aos auditores independentes, a comprovação da educaçáo continuada precisa ser realizada anualmente, mediante relatório de atividades e, por conseguinte precisam ser encaminhadas ao Conselho Regional de Contabilidade. Para que continue válido 
o registro do auditor independente no CNAI, esse profissional precisa cumprir no mínimo 40 pontos/ hora, conforme estabelece a NBC PG 12 (R3).

Oliveira (2015) destaca que o aperfeiçoamento profissional é uma necessidade em consequência das mudanças para a consolidação da convergência das normas brasileiras de contabilidade do setor privado e as de auditoria às normas internacionalmente aceitas.

Segundo Ferreira (2006) o mercado de trabalho exige gradativamente melhores qualificaçôes dos profissionais, visto que essa é a nossa realidade atual, mostrando a necessidade de se buscar mais informaçóes e consequentemente, tornando a educação continuada fundamental.

Periodicamente experimentam-se das mais diversas mutaçóes no meio acadêmico, profissional e científico, por isso é necessário para os profissionais uma reciclagem de conhecimentos, a fim de que possam se manter em dia com as mudanças inevitáveis que ocorrem ao seu redor.

\subsubsection{Campo de aplicação e obrigaçóes dos profissionais}

As obrigaçóes dos profissionais que desejam prosseguir com seu cadastro ativo, são: comprovar o cumprimento dos requisitos indicados à educação continuada, manter atualizado os seus dados cadastrais e manter regular seu registro junto ao $\mathrm{CRC}$. $\mathrm{O}$ não cumprimento dos requisitos segundo o CFC implicará na suspensão da utilização do número cadastral e na suspensão da emissão de certidão de registro no CNAI, sem prejuízo de sançôes éticas e da eventual suspensão dos registros nos órgãos reguladores.

Para se obter o registro no CNAI, o auditor necessita ser aprovado no exame de qualificação técnica, e acertar

no mínimo cinquenta por cento da prova objetiva e discursiva. $\mathrm{O}$ auditor náo precisa necessariamente estar exercendo o papel de auditor independente para obter o registro. Para os sócios, responsáveis técnicos ou que exerçam cargos administrativos nas firmas de auditoria que são registradas na CVM também será obrigatório o cadastro.

O Banco Central do Brasil é uma autarquia federal associada ao Sistema Financeiro Nacional, sendo vinculado ao Ministério da Fazenda do Brasil. Por esse motivo, os auditores independentes que pretendem atender as necessidades desta entidade, precisam obrigatoriamente possuir seu registro ativo no CNAI. Outro tipo de autarquia em que se é exigido o registro, é a Susep (Superintendência de Seguros Privados), a qual é responsável tanto pelos seguros privados, quanto pelo seguro público obrigatório, tais como o DPVAT (Danos Pessoais Causados por Veículos Automotores de Vias Terrestres).

Em outros casos é exigido o cadastro, na hipótese de o profissional ocupar cargos de gerência ou chefia na área contábil, em firmas de auditoria que são contratadas pelos órgáos citados anteriormente ou em empresas que são consideradas de grande porte.

Esses requisitos são para os que possuem obrigatoriedade em dar continuidade na educaçáo profissional. Visto isso, a Norma reforça sobre a exigência principal para manter-se válido o registro no CNAI: «Os contadores referidos no item 4, letras (a), (b), (c) e (d), aprovados em Exame de Qualificação Técnica específico, devem cumprir, dentro do total de pontos anuais, o mínimo exigido pelo órgão regulador respectivo».

Conclui-se que para o cumprimento de todos os itens listados e explicados anteriormente é fundamental a manutenção do registro profissional, e para que isso ocorra corretamente faz-se necessário que o auditor 
cumpra as condiçôes exigidas pelas normas vigentes, a fim de que esteja em conformidade para exercer suas atividades.

\subsubsection{As capacitadoras e as diretrizes para credenciamento}

Capacitadora é a entidade que promove atividades de Educação Profissional Continuada consoante às diretivas desta Norma. O seu credenciamento junto ao CFC é feito por meio de solicitação ao CEPC-CRC (Comissão de Educação Profissional Continuada do CRC) ou na falta desta, deverá ser solicitado à Câmara de Desenvolvimento Profissional do CRC, que por sua vez, enviará o pedido a CEPC-CFC.

De acordo com o item 15, da NBC PG 12 (R3) «Cabe ao profissional à verificação prévia do devido credenciamento no PEPC da atividade (cursos, eventos) que pretende realizar, bem como dos pontos que serão atribuídos. Os cursos de pós-graduação oferecidos por IES registrada no MEC estáo dispensados de credenciamento».

A validade do credenciamento de capacitadoras é por tempo indeterminado e o credenciamento dos cursos e eventos é válido até o final do exercício seguinte àquele do credenciamento, desde que preservadas as características do item 6, alínea (a), do Anexo I, podendo ser revalidado, se solicitado, desde que mantidas as condiçóes de credenciamento e aprovadas pela CEPC/CRC da respectiva jurisdição.

Capacitadoras segundo o CFC (NBC PG 12, 2017) são: CFC; CRCs; FBC; Abracicon; IBRACON; IES credenciadas pelo MEC; Instituiçóes de Especialização ou Desenvolvimento Profissional que ofereçam cursos ao público em geral; Federaçóes, Sindicatos e Associaçóes da classe contábil; Firmas de Auditoria Independente; Organizaçôes Contábeis; e Órgãos
Reguladores. Essas entidades chamadas de capacitadoras, precisam se atentar a incentivar o cumprimento à educação continuada, promovendo eventos.

\subsubsection{Os benefícios da educaçáo profissional continuada na qualidade dos serviços de auditoria}

A partir de janeiro de 2016, os contadores responsáveis pelas demonstraçóes contábeis, ou que exerçam funçóes de chefia ou gerência no desenvolvimento das demonstrações contábeis, além dos contadores com função de auditor, passam a ser obrigados ao Programa de Educação continuada do CFC.

O CFC introduziu em 2009 a NBC TA 220, onde regula o controle de qualidade na auditoria de demonstraçôes financeiras. Em se tratando de educaçáo continuada, ela se torna relevante no controle de qualidade quando os auditores precisam executar suas atividades de acordo com as normas profissionais e técnicas, e para isso é de extrema importância que o auditor esteja informado sobre as mudanças e revisóes que ocorrem nos regulamentos.

Em consonância com descrito na norma, o vice-presidente de desenvolvimento profissional do CFC (Zafra, 2017) explica seu ponto de vista acerca da importância da educação continuada para os profissionais: «O mercado exige que o profissional esteja sempre se atualizando. As mudanças na área ocorrem de maneira muito mais rápida hoje do que acontecia há 10 anos».

Reforçando o posicionamento de Zafra (2017), o vicepresidente do IBRACON, mostra a necessidade da renovação do conhecimento, a perspectiva de Sousa (2014) é:

[...], no Brasil, vivemos nos últimos 10 anos um período de mudanças intensas, principalmente com a introdução nas normas contábeis internacionais (IFRS) e normas de auditoria internacionais (ISA). Qualquer profissional 
que tenha se formado em curso superior ou técnico em Contabilidade antes de 2007 certamente aprendeu contabilidade e auditoria com base em conceitos que já se encontram ultrapassados.

Em suma, a educação é a base primordial para composição de uma sociedade mais qualificada e preparada para o futuro. Evidentemente, a educaçáo estabelece padróes oriundos de pesquisas e aprofundamento de estudos. A teoria empregada à prática edifica qualquer profissional. Desta forma, cabe ao profissional de auditoria buscar o aperfeiçoamento, e consequentemente, o destaque no meio em que se encontram.

\section{Metodologia}

A metodologia desta pesquisa quantos aos objetivos tem finalidade descritiva, pois identificou quais os benefícios trazidos pela educaçáo continuada para os auditores independentes. Quanto aos procedimentos esta pesquisa se caracterizou como levantamento ou survey, pois a obtenção de dados foi realizada por meio de um questionário aplicado via e-mail para os auditores independentes cadastrados no CNAI e vinculados ao CRCMT. Este estudo investigou os benefícios do programa da educação continuada na visão dos auditores independentes investigados. Quanto à abordagem do problema, este estudo caracteriza-se como qualitativa por estar relacionada aos levantamentos de dados sobre a motivação, expectativas e opiniōes dos auditores independentes analisados.

Os dados da pesquisa foram coletados por meio de um questionário compostos por perguntas abertas e fechadas e foram aplicadas aos auditores independentes cadastrados no CNAI ou vinculados ao CRCMT.

O informante ao responder o questionário reconheceu ao final dele, quais os maiores obstáculos enfrentados por eles (auditores independentes), qual o principal motivo para a não continuidade da educação continuada e também qual as influências trazidas pelo programa de educação continuada na sua vida pessoal e profissional.

Após a aplicação do questionário, os dados foram transferidos para uma planilha online, já que o questionário foi enviado por e-mail. Isto foi necessário para um melhor alcance dos auditores que moram nas cidades vizinhas. O questionário apresentado não teve a identificação dos auditores independentes, por não ser relevante ao objetivo da pesquisa, somente os dados obtidos por eles foram importantes para esta pesquisa.

Esta pesquisa utilizou-se do tipo de amostragem não probabilista e teve-se a utilizaçáo do tipo de plano metodológico transversal, pois o questionário foi aplicado somente uma vez aos auditores entrevistados.

A população é uma visão ampla do campo de estudo escolhido, que deverá ser delimitado para desenvolver o estudo pretendido na pesquisa. Diante do exposto, o universo desta pesquisa tem a característica em comum de ser realizada com profissionais atuantes no Estado de Mato Grosso. A população desta pesquisa foi representada por todos os auditores independentes. A amostra desta população é composta pelos auditores independentes que possuem registro ativo no CNAI e que são vinculados ao CRCMT. O site do Conselho Federal de Contabilidade disponibiliza consultar quais são os auditores que possuem registro no CNAI, tal informação abre reais possibilidades na identificação dos atores desta investigação, o qual deverá facilitar o contato com estes profissionais. No Brasil temos 349.245 contadores registrados no Sistema CFC/CRC's, destes, 3.531 mantém registro no CNAI. Já em Mato Grosso são 8.011 contadores registrados no CRCMT e destes apenas 20 possuem seus registros no CNAI.

Contabilidad y Negocios (13) 26, 2018 / ISSN 1992-1896 


\section{Descrição e Análise do Resultado}

\subsection{Resultados da pesquisa}

A pesquisa foi realizada por meio de um questionário virtual, disponibilizado em um link (por meio de um formulário web elaborado a partir do Google Forms, aplicativo do Google que permite a criação, compartilhamento e disponibilização de formulário na web) e encaminhado aos auditores independentes com registro ativo no CNAI, e respondido durante os meses de dezembro de 2017 e janeiro de 2018. O universo da investigação compreendeu 20 profissionais, dos quais 10 participaram com suas respostas aos questionamentos.
Iniciou-se o questionário com a identificação do tempo de atuação profissional do auditor independente.

Dos dez auditores entrevistados, dois exercem até três anos de função, dois de três a cinco anos, um profissional de cinco a nove anos, quatro de dez a quinze anos e apenas um acima de quinze anos.

Como pode ser observado no gráfico 2 a maioria dos entrevistados já mantém seu registro no CNAI ou CVM, há mais de 9 e até 15 anos, somando, portanto, $50 \%$ dos participantes. Os outros $50 \%$ estão assim divididos: $20 \%$ há mais de 3 até 5 anos; nas faixas de até 3 anos, de mais de 5 até 9 anos e acima

\section{Gráfico 1. Tempo na função}

1. Há quanto tempo exerce a função de auditor (a) contábil?

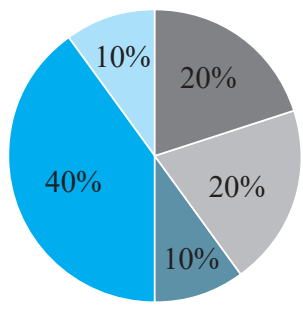

Até 3 anos De 3 a 5 anos $\square$ De 5 a 9 anos $\square$ De 10 a 15 anos Acima de 15 anos Fonte: Elaborado pelos autores, 2018.

Gráfico 2. Tempo de registro ativo no CNAI ou CVM

2. Há quanto tempo possui registro no CNAI

(Cadastro Nacional dos Auditores Independentes) ou CVM?

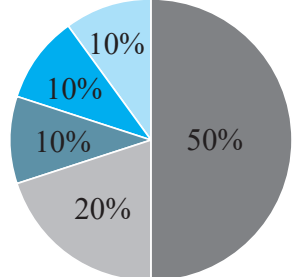

Até 3 anos De 3 a 5 anos $\square$ De 5 a 9 anos $\square$ De 10 a 15 anos $\square$ Acima de 15 anos Fonte: Elaborado pelos autores, 2018. 
de 15 anos, registra-se $10 \%$ para cada uma das faixas, respectivamente.

Existem regras para que o profissional continue tendo seu registro junto ao CNAI, uma delas, é o tema desta pesquisa, que é a educação profissional continuada, a falta dela implica na cassação do mesmo.

Quando questionados se algum dos entrevistados, já tiveram seu registro cassado, todos, em unanimidade responderam que não.
Adentrando no assunto central da pesquisa, perguntou-se aos profissionais se a educação continuada é um mecanismo eficaz na atualização profissional, dos dez entrevistados um respondeu que não, conforme demonstrado a seguir.

A importância da educação continuada está justamente ligada a sempre buscar a atualização profissional, visto isso, perguntou-se aos entrevistados se eles realizaram ou realizam algum curso após a graduação, e os dados obtidos estão explicitados a seguir.

\section{Gráfico 3. Educação continuada como mecanismo eficaz}

4. Em sua opinião, a educação continuada é um mecanismo eficaz na actualização profissional?

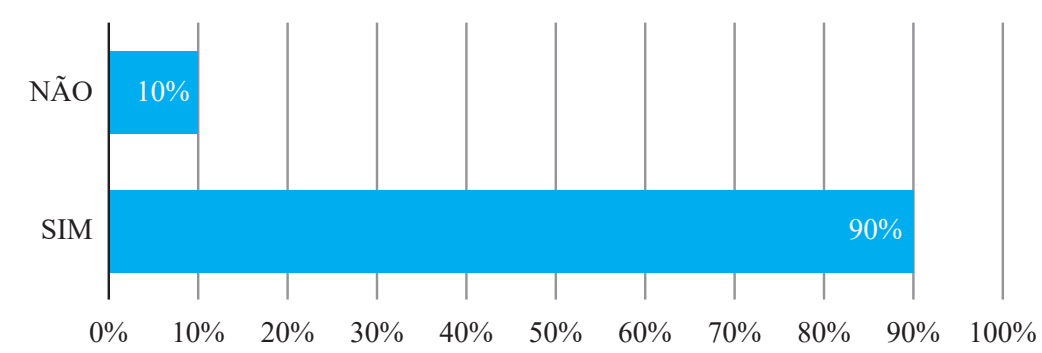

Fonte: Elaborado pelos autores, 2018.

\section{Gráfico 4. Continuidade educacional após a graduação}

5. Você realiza Especialização / Mestrado / Doutorado?

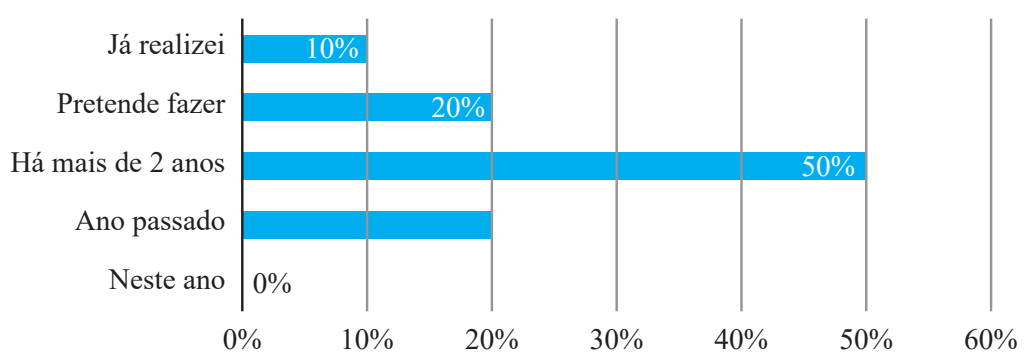

Fonte: Elaborado pelos autores, 2018. 
Nota-se que $80 \%$ dos auditores entrevistados deram continuidade aos seus estudos, após a graduação contábil, e os $20 \%$ restantes pretendem dar seguimento, algo relevante, já que, a falta de atualização, tende a fazer com que o profissional da área de auditoria deixe de acompanhar a evolução tecnológica e da legislação.

Atualmente a tecnologia favorece a atuação dos profissionais, principalmente quando existem criaçóes e retificaçôes das normas contábeis e da legislação, e não será sempre que o auditor terá tempo para fazer um curso ou uma especializaçáo a cada vez que isso ocorrer. Assim, questionou-se aos auditores, quanto à utilização de sites para pesquisar assuntos relacionados à área de auditoria, cujo resultado aponta que 60\% pesquisam sempre na internet e que $40 \%$ às vezes buscam atualizaçôes por meio de sites, conforme gráfico abaixo.

Em observância às opiniōes dos auditores independentes, contatou-se em escala de importância, enumeradas de 1 a 5 , referente ao desenvolvimento profissional e educação continuada, que $70 \%$ acreditam que o programa é importante para o profissional de auditoria, $10 \%$ acham que é razoavelmente importante e $20 \%$ avaliam que é muito importante.

\section{Gráfico 5. Internet e pesquisas contábeis periódicas}

6. Você pesquisa sites na internet para adquirir conhecimientos contábeis e realizar pesquisas na área?

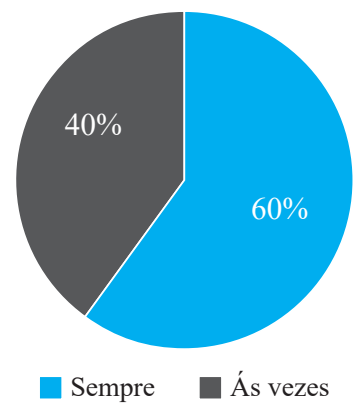

Fonte: Elaborado pelos autores, 2018.

\section{Gráfico 6. Escala de importância da educação continuada}

7. Em sua opinião, qual o grau de importância da educação continuada em relação ao seu desenvolvimento profissional?

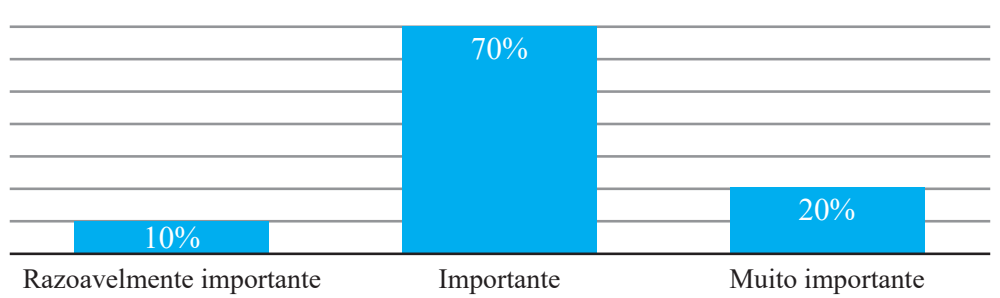

Fonte: Elaborado pelos autores, 2018. 


\section{Gráfico 7. Escala de importância para outros auditores}

8. Em sua opinião, qual o grau de importância que seus colegas dão à educação continuada?

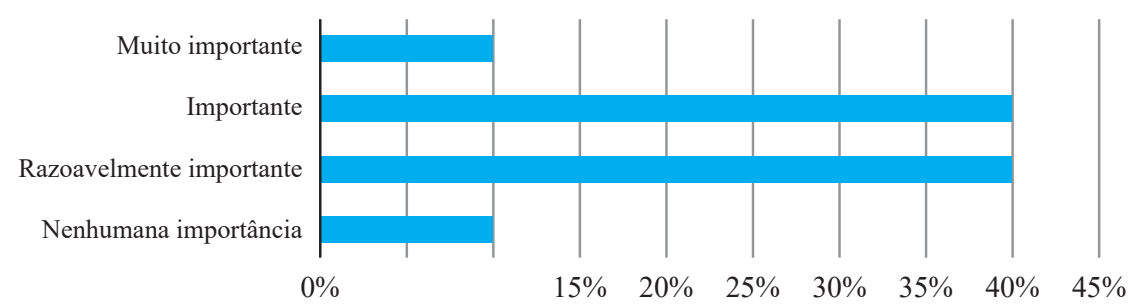

Fonte: Elaborado pelos autores, 2018.

Perguntado sobre a sua opinião em relação aos que colegas de trabalho pensam a respeito da educaçáo profissional continuada, o resultado foi o seguinte: $40 \%$ acreditam que seus colegas acham razoavelmente importante a educação continuada, $40 \%$ importante, $10 \%$ avaliam que seus colegas consideram muito importante e $10 \%$, que acreditam que seus colegas dão nenhuma importância para o programa de educação profissional.

Em relação às perguntas abertas, os dez auditores (agora nomeados de A a J), foram convidados a destacar os maiores obstáculos enfrentados por eles na realização de um processo de auditoria contábil:

\section{Quadiro 1. Resposta sobre os maiores obstáculos enfrentados na auditoria}

\begin{tabular}{|c|l|}
\hline Auditor & \multicolumn{1}{|c|}{ Resposta } \\
\hline A & $\begin{array}{l}\text { Atuo com clientes do agronegócio, meu maior obs- } \\
\text { táculo é encontrar profissionais com a expertise } \\
\text { necessária para exercer a profissão de contador, visto } \\
\text { que saem muito limitados das instituiçóes acadêmi- } \\
\text { cas. }\end{array}$ \\
\hline B & $\begin{array}{l}\text { Sistema de informação, insegurança jurídica e } \\
\text { ausência de estrutura organizacional das empresas }\end{array}$ \\
\hline
\end{tabular}

\begin{tabular}{|c|c|}
\hline Auditor & Resposta \\
\hline $\mathrm{C}$ & $\begin{array}{l}\text { Planejamento de programa adequado para a reali- } \\
\text { zaçáo do trabalho de forma que atinja o objetivo } \\
\text { para o qual foi contratado. }\end{array}$ \\
\hline $\mathrm{D}$ & Acesso a Informação \\
\hline E & $\begin{array}{l}\text { A maior dificuldade é quando há resistência dos } \\
\text { envolvidos, ocorrendo, portanto, um boicote na } \\
\text { realização da auditoria, sendo necessário a saída de } \\
\text { campo. }\end{array}$ \\
\hline $\mathrm{F}$ & Colaboração de outros setores da empresa auditada \\
\hline G & $\begin{array}{l}\text { Prazo, entre o período de realizaçáo da auditoria até } \\
\text { a entrega do relatório, são curtos. }\end{array}$ \\
\hline $\mathrm{H}$ & $\begin{array}{l}\text { Disponibilização de Cursos no estado de Mato de } \\
\text { Grosso que somam pontos para Educação Conti- } \\
\text { nuada. Quanto a cursos, o Conselho Regional de } \\
\text { Contabilidade do MT náo divulga adequadamente. }\end{array}$ \\
\hline I & $\begin{array}{l}\text { Adequação do cliente nas normas brasileiras e inter- } \\
\text { nacionais de auditoria }\end{array}$ \\
\hline $\mathrm{J}$ & $\begin{array}{l}\text { O principal desafio do auditor é a compreensão dos } \\
\text { clientes sobre o que é o processo de auditoria, escla- } \\
\text { recer que o objetivo é auxiliar em seus processos e } \\
\text { controles, além de certificar que os critérios adota- } \\
\text { dos estão coerentes. }\end{array}$ \\
\hline
\end{tabular}

Fonte: Elaborado pelos autores, 2018. 
Questionou-se ainda, a respeito dos benefícios que o programa de educação continuada proporciona ao meio profissional:

\section{Quadro 2. Resposta sobre os benefícios da educação continuada}

\begin{tabular}{|c|c|}
\hline $\begin{array}{l}\text { Entre- } \\
\text { vistado }\end{array}$ & Resposta \\
\hline A & $\begin{array}{l}\text { Na realidade quem trabalha em firmas de auditoria } \\
\text { passa por diversos treinamentos anuais, entáo a edu- } \\
\text { cação continuada em minha opinião apenas cumpre } \\
\text { um protocolo. Para quem náo atua na área, acredito } \\
\text { que seja importante para manter-se atualizado. }\end{array}$ \\
\hline B & $\begin{array}{l}\text { Eficiência na execução do processo de auditoria, haja } \\
\text { vista a universalidade de normas e legislação que } \\
\text { envolvem a profissão e o mercado, nos âmbitos fiscais } \\
\text { e regulamentares. }\end{array}$ \\
\hline $\mathrm{C}$ & $\begin{array}{l}\text { Atualização profissional. } \\
\text { Aquisição de novos conhecimentos } \\
\text { Relacionamento com novos colegas, troca de infor- } \\
\text { maçôes e discussão de assuntos importantes. }\end{array}$ \\
\hline $\mathrm{D}$ & (Não houve posição) \\
\hline $\mathrm{E}$ & $\begin{array}{l}\text { O aspecto positivo, é sempre a reciclagem do profis- } \\
\text { sional, devido as constantes alteraçóes nas normas e } \\
\text { legislaçóes que afetam seu trabalho. }\end{array}$ \\
\hline $\mathrm{F}$ & $\begin{array}{l}\text { Força o profissional a melhorar seu perfil de conhe- } \\
\text { cimento }\end{array}$ \\
\hline G & $\begin{array}{l}\text { As normas de auditoria brasileiras estáo em processo cons- } \\
\text { tante de atualizaçáo, com IFRS, reflexo disso cai sobre os } \\
\text { modos de como ocorre os registros contábeis corretos. }\end{array}$ \\
\hline
\end{tabular}

\begin{tabular}{|c|l|}
\hline $\begin{array}{c}\text { Entre- } \\
\text { vistado }\end{array}$ & \multicolumn{1}{c|}{ Resposta } \\
\hline $\mathrm{H}$ & $\begin{array}{l}1 \text { - Entendimento e compreensão adequado as novas } \\
\text { normas e suas alteraçóes; } \\
2 \text { - Avaliação e aplicação correta dos procedimentos } \\
\text { de auditoria; } \\
\text { 3- Fundamentar adequadamente os relatórios e a opi- } \\
\text { niáo do auditor; } \\
\text { 4- Compreender, exigir e aplicar os riscos da auditoria } \\
\text { e formalizar os riscos da governança. }\end{array}$ \\
\hline $\mathrm{I}$ & $\begin{array}{l}\text { Aprimoramento nos conhecimentos e desenvolvi- } \\
\text { mento na qualidade dos trabalhos realizados }\end{array}$ \\
\hline $\mathrm{J}$ & $\begin{array}{l}\text { Em decorrência das constantes alteraçôes dos critérios } \\
\text { contábeis, o acompanhamento destes é fundamental, } \\
\text { sendo a educaçáo continuada um importante instru- } \\
\text { mento para o desenvolvimento profissional. }\end{array}$ \\
\hline
\end{tabular}

Fonte: Elaborado pelos autores, 2018.

No que tange a avaliação como usuário dos cursos ministrados pelas capacitadoras no Brasil, vimos que $70 \%$ dos auditores afirmam que os cursos são bons e os outros $30 \%$ são indiferentes sobre o assunto.

Pediu-se ainda, sugestôes dos entrevistados, referente ao que poderia melhorar no programa de educação continuada. Os auditores expressaram em sua grande maioria acerca dos cursos que são ministrados pelos conselhos o seguinte.

\section{Gráfico 8. Avaliaçáo dos currsos oferecidos pelas capacitadoras no Brasil}

11. Como você avalia os cursos de educação profissional continuada que são ofrecidos pelas Capacitadoras no Brasil?

\begin{tabular}{ccccc}
\hline & \multicolumn{3}{c}{$70 \%$} \\
\hline $0 \%$ & $0 \%$ & $30 \%$ & & $0 \%$ \\
\hline RUIM & REGULAR & INDIFERENTE & BOM & EXCELENTE
\end{tabular}

Fonte: Elaborado pelos autores, 2018. 
Quadro 3. Sugestóes de melhoria no programa de educaçáo continuada

\begin{tabular}{|c|c|}
\hline Auditor & Resposta \\
\hline A & $\begin{array}{l}\text { Que sua comprovação fosse realizada no meio do ano, } \\
\text { já que em janeiro estamos em período de final e emis- } \\
\text { são de DF, e por vezes náo estamos disponíveis para } \\
\text { realizar a comprovação }\end{array}$ \\
\hline $\mathrm{B}$ & Mais efetividade \\
\hline $\mathrm{C}$ & $\begin{array}{l}\text { Realização de cursos em todos os CRC's, facilitando o } \\
\text { acesso a todos os interessados em novos conhecimentos. }\end{array}$ \\
\hline $\mathrm{D}$ & Regionalização na oferta de cursos e eventos \\
\hline $\mathrm{E}$ & Melhor acompanhamento e capacitação dos professores \\
\hline $\mathrm{F}$ & $\begin{array}{l}\text { Cadastrar outros tipos de cursos, como gestão, proje- } \\
\text { tos e liderança }\end{array}$ \\
\hline G & Leque maior de cursos. \\
\hline $\mathrm{H}$ & $\begin{array}{l}\text { Devido ao tempo escasso dos auditores sugiro maior } \\
\text { disponibilizaçáo de cursos não presenciais - Elearning } \\
\text { pelos CRC's e CFC. }\end{array}$ \\
\hline I & Não tenho sugestôes de melhoria \\
\hline $\mathrm{J}$ & $\begin{array}{l}\text { Cursos mais objetivos e direcionados, náo somente } \\
\text { para o cumprimento dos pontos obrigatórios do PEC. }\end{array}$ \\
\hline
\end{tabular}

Fonte: Elaborado pelos autores, 2018.

O quadro a seguir, representa as respostas obtidas com relação a pergunta no 13 , que tem por objetivo saber se os auditores entrevistados sabem classificar corretamente os três tipos de auditoria que podem ser empreendidos nas organizaçóes de negócios e do setor público.
Quadro 4. Pergunta teórica quanto aos tipos de auditoria

\begin{tabular}{|c|c|c|c|c|c|}
\hline & $\begin{array}{c}\text { Auditoria } \\
\text { interna }\end{array}$ & $\begin{array}{c}\text { Auditoria } \\
\text { operacio- } \\
\text { nal }\end{array}$ & $\begin{array}{c}\text { Auditoria } \\
\text { contábil }\end{array}$ & $\begin{array}{c}\text { Auditoria } \\
\text { externa ou } \\
\text { independente }\end{array}$ & $\begin{array}{c}\text { Auditoria } \\
\text { de confor- } \\
\text { midade }\end{array}$ \\
\hline A & & $\mathrm{X}$ & $\mathrm{X}$ & $\mathrm{X}$ & \\
\hline $\mathrm{B}$ & $\mathrm{X}$ & $\mathrm{X}$ & & $\mathrm{X}$ & \\
\hline $\mathrm{C}$ & & $\mathrm{X}$ & $\mathrm{X}$ & $\mathrm{X}$ & \\
\hline $\mathrm{D}$ & & $\mathrm{X}$ & $\mathrm{X}$ & & $\mathrm{X}$ \\
\hline $\mathrm{E}$ & $\mathrm{X}$ & & & $\mathrm{X}$ & $\mathrm{X}$ \\
\hline $\mathrm{F}$ & $\mathrm{X}$ & $\mathrm{X}$ & & $\mathrm{X}$ & \\
\hline $\mathrm{G}$ & & & & $\mathrm{X}$ & \\
\hline $\mathrm{H}$ & & & & $\mathrm{X}$ & \\
\hline $\mathrm{I}$ & $\mathrm{X}$ & & $\mathrm{X}$ & $\mathrm{X}$ & \\
\hline $\mathrm{J}$ & $\mathrm{X}$ & & & $\mathrm{X}$ & $\mathrm{X}$ \\
\hline
\end{tabular}

Fonte: Elaborado pelos autores, 2018.

Nota-se que apenas um dos entrevistados classificou corretamente os três tipos de auditoria que podem ser executados juntos às entidades auditadas e que representam o mix de mercado para os profissionais que atual nesta área.

Por último, os entrevistados foram indagados a respeito do exame de qualificaçáo técnica promovido pelo CFC, em grau de importância constatou-se que $60 \%$ afirma ser importante, enquanto $30 \%$ indicam que é muito importante e $10 \%$ razoavelmente importante.

\section{Gráfico 9. Grau de importância sobre o exame de qualificação técnica}

14. Como você classifica o exame de qualificação técnica promovido pelo Conshelho Federal de Contabilidade, enquanto exigência dos exercícios das funções de Auditor Independente?

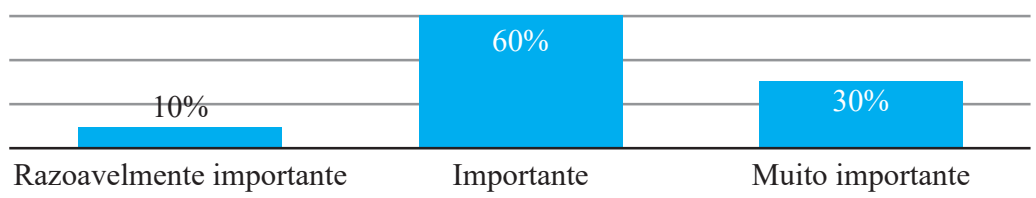

Fonte: Elaborado pelos autores, 2018 


\subsection{Discussóes e análise dos resultados}

Os dados descritos anteriormente permitem dizer que os auditores independentes que participaram da pesquisa realizada são unânimes em afirmar que a educação continuada é fator relevante para a melhoria da qualidade dos serviços de auditoria e de atualizaçáo como mecanismo de desenvolver a competência e o zelo profissional. Isso mostra a real preocupação dos entrevistados em se manterem atualizados para desempenhar as funçôes de auditoria com integridade e independência de atitude mental.

Identificou-se por meio do questionário, o tempo que os entrevistados exercem a função de auditor, e o resultado colhido foi de que a maioria deles possuem experiência no ramo há mais de 10 anos, trazendo mais confiabilidade para a pesquisa. Conforme diz Perez Júnior (1995), sobre as principais técnicas de auditoria, o autor relata que uma delas é a observação das atividades, onde se exige mais a vivência e experiência do auditor, fazendo com que o mesmo consiga detectar as deficiências, erros, problemas, através do conhecimento e vivência do profissional.

Verificou-se que grande parte dos investigados estão no ramo de auditoria há mais de dez anos, logo, quando questionados acerca do registro ativo no CNAI, obteve-se que a metade deles possuem o registro há mais de três anos. Seguindo a mesma linha de questionamento, perguntou-se aos auditores, se algum teve seu CNAI suspenso e em unanimidade responderam que não, adequando a NBC PA 12, a qual exige que para que isso não ocorra, os auditores precisam cumprir a meta anual de 40 pontos. Esse resultado mostra que os auditores cadastrados no CNAI, com registro no CRCMT vêm cumprindo com as exigências das NBC Profissionais de Auditoria, o que permite dizer que se classificam em relação de proximidade com as diretrizes da literatura especializada.
Para identificar a realidade de vivência dos entrevistados, perguntou-se sobre a eficácia do programa educacional, onde mais uma vez, a maioria disse ser eficaz. No que tange às NBC, a educação continuada busca ser uma ferramenta de atualização profissional para os auditores. Esse resultado mostra que os entrevistados estáo a par com os objetivos do programa de educação continuada cujo objetivo está disposto no item 2 da NBC PG 12 (R2), (2016). Assim, pode-se dizer, que a visáo dos auditores que responderam a esta investigação pode ser classificada em relação de proximidade com as diretrizes da literatura especializada, ou seja, todos são unânimes em afirmar que a educação continuada é fundamental para o exercício das atividades de auditoria com dignidade e qualidade.

$\mathrm{Na}$ atualidade para ter um diferencial no mercado, uma graduação de ensino superior já não é o bastante, pois cada vez mais faculdades e universidades estão propondo novos cursos de pós-graduação, mestrados e doutorados para o mercado. Visto isso, nota-se que os investigados em sua totalidade já fizeram uma especialização, ou os que não fizeram, que são bem poucos, pretendem fazer, tornando assim, o mercado relativamente mais aquecido e competitivo.

As modernizaçôes e os avanços tecnológicos ocorridos nos últimos anos obrigaram tanto as empresas, quanto os auditores a se adaptarem às novas exigências do mercado, isto também pode ser visto nas respostas dos auditores quando foi perguntado sobre fazer pesquisas na internet, todos responderam que utilizam desta ferramenta, estando em concordância com o que Ferreira (2006, p. 22) afirmou: «Quem não acompanhar as mudanças científicas e tecnológicas, prematuramente estará inabilitado para o trabalho e para a vida em sociedade que, contraditoriamente, pela própria evolução, produziu também o não trabalho». 
Em observância às opiniōes dos auditores independentes $70 \%$ acreditam, que o programa é importante para o profissional de auditoria. Oliveira (2015), destaca que a educação continuada, passa de importante a ser uma necessidade, visto que existem muitas convergências no âmbito contábil. Quando questionados sobre o grau de importância que seus colegas de trabalho dão a educação profissional continuada, muitos acreditam que eles dão muita importância ao programa, e apenas um pensa que seus colegas de profissão não dão a mínima importância, com isso faz-se analisar mais a respeito dos números e CNAIs caçados anos após anos.

Os entrevistados foram convidados a destacar os maiores obstáculos enfrentados na execução de seu trabalho e em suma, as respostas dos entrevistados resumem-se na falta de acesso à informação, falta de conhecimento acadêmico e profissional, seja pelos clientes ou pelos próprios auditores que acabaram de chegar ou que já estão no ramo, onde faz-se necessário frisar novamente acerca da importância da educaçáo continuada no ramo profissional. De acordo com Cavalcanti (2007) para assumir responsabilidade por uma Auditoria, o profissional precisa ter conhecimento da atividade da entidade auditada, de forma suficiente para que lhe seja possível identificar, analisar e compreender as transaçóes realizadas pela mesma e as práticas contábeis aplicadas, que possam ter efeitos relevantes sobre a posição patrimonial e financeira da entidade.

Acerca dos benefícios da educação profissional continuada, as respostas resumem-se ao aprimoramento profissional, atualização profissional, aquisição de novos conhecimentos e troca de informaçóes com colegas do mesmo ramo. O vice-presidente de desenvolvimento profissional do CFC aponta:

Para seguir atuando no mercado, atualmente, o profissional precisa estar cada vez mais preparado.
A internacionalizaçáo das normas aplicadas ao setor e a informatização de sistemas e processos têm provado mudanças muito rápidas e profundas. É indispensável que o profissional da contabilidade esteja sempre se atualizando. O Programa de Educação Profissional Continuada vem a esse encontro.

Sobre a EPC ser um mecanismo, os entrevistados disseram unanimemente que a educação continuada é um meio de atualização profissional, visto que existem alteraçôes de leis e normas periodicamente. Outros foram mais além e afirmaram que a educação continuada é apenas um protocolo a ser seguido, enquanto outros destacam que o programa é positivamente uma reciclagem de aprimoramento profissional. O CFC (NBC PG 12, 2017) confirma sobre a EPC:

[...] atividade formal e reconhecida pelo CFC, que visa manter, atualizar e expandir os conhecimentos técnicos e profissionais, indispensáveis à qualidade e ao pleno atendimento às normas que regem o exercício da atividade de auditoria de demonstraçôes contábeis.

No que tange à avaliação dos entrevistados a respeito dos cursos oferecidos pelas capacitadoras, 70\% deles afirmam ser bom, enquanto $30 \%$ são indiferentes quanto ao assunto, um ponto a ser avaliado neste contexto, está justamente relacionado a falta de investimento na disponibilidade de cursos que valham pontos ao CNAI, é de suma importância, visto que atualmente a oferta náo supri a demanda do mercado.

Segundo a NBC PA 12 (R3), sobre melhorias nos cursos de capacitação:

Considera-se aquisição de conhecimento as atividades presenciais, à distância ou mistas, incluindo auto estudo, estudo dirigido, e-learning e equivalentes, sobre temas que contribuam para a melhoria da performance do profissional, com conteúdo de natureza técnica e profissional, relacionados ao PEPC.

Contabilidad y Negocios (13) 26, 2018 / ISSN 1992-1896 
Em relação às sugestôes de melhorias para o programa de educação continuada, onde grande parte dos auditores, afirmaram que existe escassez de cursos ofertados pelas capacitadoras e além de sugerirem maior leque de cursos, frisaram a importância de maiores ofertas nos cursos EAD (ensino a distância), já que a falta de tempo, ás vezes impossibilita ao profissional que faça mais cursos de aprimoramento.

No que tange às opiniōes e sugestões, fez-se uma questâo básica e teórica referente aos tipos de auditoria, na qual sua classificação é subdividida em três, sendo: auditoria contábil, onde busca-se avaliar as demonstraçôes financeiras da empresa, auditoria operacional, onde constata-se se o sistema de controle da empresa é eficaz e a auditoria de conformidade que é avaliar se os procedimentos da empresa estão em conformidade com as normas estabelecidas para o tipo de atividade em que a empresa se encontra.

Segundo Briti (2010, p. 26):

Auditoria contábil envolve obtenção e avaliação de evidências a respeito das demonstraçôes contábeis de uma entidade, para emissão de parecer se sua apresentação está adequada, de acordo com Princípios Contábeis Geralmente Aceitos (PCGA).

Por esse motivo, considera-se que, o objetivo da auditoria contábil resume-se em apurar as demonstraçóes financeiras, de maneira que o responsável tenha comprovações para emitir seu parecer, sobre a situação usual da empresa.

Auditoria operacional visa um controle periódico preciso, temos Sá (2009) que apresenta a auditoria operacional como sendo o exame do desempenho administrativo em face do patrimônio em gestão, ou seja, identificar se a vida da empresa está em situação proveitosa.
Diante dos fatos mencionados podemos concluir que, a auditoria operacional analisa o desempenho interno mostrando como está de fato o funcionamento da entidade, sempre em busca de implantação de melhorias, e recomendaçóes viáveis para um melhor funcionamento intrínseco.

A título de conceito, Silva (2016, p. 12) ao definir auditoria de conformidade assim expressa: «Compreende a obtenção e avaliação de evidências para identificar se determinadas atividades operacionais ou financeiras $\mathrm{da}$ entidade examinada estáo sendo executadas de acordo com regulamentos, regras ou condiçóes estabelecidas». Em suma, a auditoria de conformidade é quem vai confirmar se as atividades da empresa estáo em concordância com as regulamentaçôes presentes, ou seja, é ela quem fará a verificação do cumprimento legal, a fim de evitar dificuldades no andamento da entidade.

Ao fazer a análise das respostas, pode-se observar que apenas um auditor respondeu corretamente à questão aplicada, com base nisto pode-se afirmar que ainda existe limitação de conhecimento destes profissionais ou atualização.

A respeito do exame de qualificação técnica que é promovido pelo Conselho Federal de Contabilidade, os entrevistados afirmam ser de razoavelmente importante a muito importante, tendo sua maior parte afirmada em ser importante, e de acordo com o CFC (NBC PA $13,2015)$ o objetivo principal é de «[...] auferir o nível de conhecimento e a competência técnico-profissional necessária para atuação na área da Auditoria Independente». Esse teste torna-se fundamental àqueles que desejam seguir carreira em auditoria.

O contador que desejar atuar como auditor independente deve se submeter ao exame de qualificação técnica, em sendo aprovado é devidamente registrado 
no CNAI. O contador não precisa necessariamente estar exercendo o papel de auditor independente para obter o registro, basta se prestar o exame e se aprovado será registrado automaticamente no referido cadastro. Os sócios, responsáveis técnicos ou que exerçam cargos administrativos nas firmas de auditoria que são registradas na CVM também estão obrigados a obterem seus registros no CNAI.

Por fim, é oportuno ressaltar que para manter seu registro no CNAI esses profissionais individualmente precisam acumular 40 pontos em cursos, seminários, congressos, encontros, produção científicas e outras tarefas, conforme regulamentado na NBC PG 12 (R3) - Educação Profissional Continuada, cuja última atualização ocorreu em dezembro de 2017.

\section{Conclusóes}

O objetivo central deste estudo foi o de identificar os benefícios da exigência ao cumprimento do programa de educação continuada para os auditores independentes com registro no CNAI, e o mesmo foi atingido na medida em que com base em informações colhidas por meio de questionário, os auditores em seu âmbito geral, disseram que a exigência é uma forma de aprimoramento, atualização e reciclagem profissional.

Os entrevistados mostraram-se preocupados com o seguimento em sua carreira, porém ao mesmo tempo observou-se que em uma pergunta básica e teórica, mais de $80 \%$ dos auditores questionados não puderam responder corretamente, concluindo que a pratica e a teoria precisam andar juntas, e serem periodicamente revistas.

Recomenda-se aos estudantes de ciências contábeis que pretendam seguir a carreira de auditoria, e qualquer outra área de contabilidade, além da graduação, participe de cursos de atualização e até pós-graduação como forma de adquirir conhecimento e aumentar seu poder competitivo para ingressar no mercado de trabalho.

Os resultados discutidos anteriormente apontam a necessidade de que os sistemas CFC/CRC's implementem a educação profissional continuada em todos os níveis de conhecimento da área contábil, por meio de ofertas de cursos nas modalidades presenciais e a distância, bem como incentivando as demais capacitadoras adotarem a mesma filosofia de trabalho.

É relevante recomendar que instituiçóes acadêmicas de ensino superior que ofertem cursos de bacharelado em Ciências Contábeis incluam em suas matrizes curriculares uma disciplina específica para discutir as Normas Brasileiras de Contabilidade, incluindo em seu conteúdo seminários sobre educação profissional continuada. Essa medida é de suma importância para que o aluno, futuro profissional, possa estar mais bem preparado para enfrentar os desafios do mercado de trabalho.

\section{Referências}

Almeida, M. C. (2012). Auditoria: Um Curso Moderno e Completo. 8. ed. São Paulo: Atlas.

Attie, W. (2011). Auditoria: Conceitos e Aplicaçôes. 6. ed. São Paulo: Atlas.

Briti, M. L. (2010). Auditoria Operacional: papel e importância para a sistematização de processos e procedimentos de compras de uma empresa do ramo de sementes de Rondonópolis. 2010. 80 f. Dissertação (Bacharelado em Ciências Contábeis) - Instituto de Ciências Humanas e Sociais, Universidade Federal de Mato Grosso, Rondonópolis.

Cavalcanti, M. A. (2007). Auditoria: Um curso moderno e completo. 6. ed. São Paulo: Atlas.

Conselho Federal de Contabilidade (2006). NBC P 4 Norma para Educação Profissional Continuada. Atualizada em 23 de julho de 2006. Recuperado em 07 ago. 2017, de http//www.cfc.org.br

Contabilidad y Negocios (13) 26, 2018 / ISSN 1992-1896 
Conselho Federal de Contabilidade (2009). NBC PA 01 Controle de Qualidade para Firmas (Pessoas Juridicas e Físicas) de Auditores Independentes. Aprovada em 27 de novembro de 2009. Recuperado em 07 ago. 2017, de http//www.cfc.org.br

Conselho Federal de Contabilidade (2011). NBC PA 11 - Revisão Externa de Qualidade pelos Pares. Aprovada em 21 de fevereiro de 2011. Recuperado em 07 ago. 2017, de http//www.cfc.org.br

Conselho Federal de Contabilidade (2015). NBC PA 13 (R2) - Exame de Qualificação Técnica. Aprovada em 21 de agosto de 2015. Recuperado em 07 ago. 2017, de http//www.cfc.org.br

Conselho Federal de Contabilidade (2017). NBC PA 290 (R2) - Independência: Trabalhos de Auditoria e Revisão. Aprovada em 26 de maio de 2017. Recuperado em 07 ago. 2017, de http//www.cfc.org.br

Conselho Federal de Contabilidade (2017). NBC PG 12 (R3) - Educação Profissional Continuada. Aprovada em 06 de dezembro de 2016. Recuperado em 19 jan. 2018, de http//www.cfc.org.br

Conselho Federal de Contabilidade (). Resolução 1.328 - Estrutura das Normas Brasileiras de Contabilidade. Aprovada em 18 de março de 2011. Recuperado em 07 de ago. 2017, de http//www.cfc.org.br

Crepaldi, S. A. (2009). Auditoria Contábil: Teoria e Prática. 5. ed. São Paulo: Atlas.

Ferreira, N. S. C. (2006). Formaçâo continuada e gestão da educaçáo no contexto da cultura globalizada. 2 ed. Sáo Paulo: Cortez.

Franco, H., \& Marra, E. (2009). Auditoria Contábil: Normas de Auditoria, Procedimentos e papéis de trabalho, programas de auditoria, relatórios de auditoria. $4 \mathrm{ed}$. atualizada. São Paulo: Atlas.

Longo, C. G. (2011). Manual de auditoria e revisão de demonstraçôes financeiras. 2. ed. São Paulo: Atlas.

Marion, J. C. (2015). Contabilidade Empresarial. 17. ed. São Paulo: Atlas.
Niyama, J. K., Costa F. M., Dantas, J. A. \& Borges, E. F. (2011). Evolução da regulação da auditoria independente no Brasil: análise crítica, a partir da teoria da regulação. Advances in Scientific and Applied Accounting, 4(2), 127-161. https://doi.org/10.14392/ asaa.2011040201

Oliveira, J. (1 outubro de 2015). Responsáveis técnicos por balanços contábeis terão que cumprir educação continuada. Comunicação CFC, [S.l.], online. Recuperado em 26 ago. 2017, de http://portalcfc.org.br/noticia. php?new $=23404$

Perez Júnior, J. H. (1995). Auditoria de Demonstraçóes Contábeis: Normas e Procedimentos. São Paulo: Atlas.

Pinho, R. C. S. (2007). Fundamentos de Auditoria: Auditoria Contábil, Outras Aplicaçôes de Auditoria. São Paulo: Atlas.

Sá, A. L. (2009). Curso de Auditoria. 10. ed. São Paulo: Atlas.

Silva, A. R. (2016). Conceito e âmbito da Auditoria: Noçóes preliminares. Rondonópolis. (Apostila).

Sousa, C. (2014). A importância da Educação Continuada. Recuperado em 26 ago. 2017, de http://www.ibracon. com.br/ibracon/Portugues/detSalaImprensaRelease. php? cod=1947

Wanderley, C. A. N. (2011). Auditoria: Teoria e Questóes. [S.l.]: Ferreira.

Zafra, N. (31 de março de 2017). CVM coloca em audiência norma que reforça necessidade de Educação Continuada. Oliveira, Juliana. Conselho Federal de ContabilidadeCFC. Recuperado em 28 ago. 2017, de http://cfc.org. $\mathrm{br} /$ noticias/cvm-coloca-em-audiencia-norma-que-reforca-necessidade-de-educacao-continuada/

Fecha de recepción: 12 de mayo de 2018 Fecha de aceptación: 30 de mayo de 2018 Correspondencia:draloisio@ipeac.com.br wellenkayzi@gmail.com sniveiros@hotmail.com 